\title{
Gender Differences in Thermal Comfort on Pedestrian Streets in cold and transitional seasons in Severe Cold Regions in China
}

\author{
Hong Jin ${ }^{a}$, Siqi Liu ${ }^{a}$, Jian Kanga, b, * \\ aSchool of Architecture, Harbin Institute of Technology; Key Laboratory of Cold Region Urban \\ and Rural Human Settlement Environment Science and Technology, Ministry of Industry and \\ Information Technology, No. 66, Xidazhi Street, Harbin, Heilongjiang, China \\ bUCL Institute for Environmental Design and Engineering, The Bartlett, University College \\ London (UCL), Central House, 14 Upper Woburn Place, London WC1HONN, UK \\ * Corresponding author
}

\begin{abstract}
Some non-meteorological elements can affect thermal comfort in outdoor spaces; among these, gender is a significant factor. Based on a field study conducted during cold and transitional seasons in Harbin, which is in a severe cold region, this study analyses gender differences in thermal comfort by considering three factors: thermal comfort level, affecting factors, and self-regulation. Regarding thermal comfort level, the mean thermal sensation vote (MTSV) under the same universal thermal climate index (UTCI) is lower for females compared to males. In transitional seasons, females' neutral temperature $\left(23.2^{\circ} \mathrm{C} \mathrm{UTCl}\right)$ was higher than males' $\left(19.8{ }^{\circ} \mathrm{C}\right.$ UTCI). In cold season, the UTCI range of males' acceptable ratio to thermal environment higher than $80 \%$ was 15.34 to $8.09{ }^{\circ} \mathrm{C}$. This ratio for females was always below $80 \%$, and only approached $80 \%(79.24 \%)$ at $11.33{ }^{\circ} \mathrm{C} \mathrm{UTCl}$. Regarding thermal preference, in the same thermal environment, females were more likely to prefer higher temperatures, while males were more likely to prefer lower wind speeds. When exposed to the same solar irradiation intensity, a higher proportion of females (than males) expected stronger sunshine, regardless of the solar radiation level. Regarding factors affecting thermal comfort, only air temperature influenced thermal comfort in the cold season. In transitional seasons, air temperature and solar radiation impacted thermal comfort. Regarding ways to regulate thermal comfort, females wear thicker clothes in the cold season, while males actively move about. Therefore, males are more likely to exercise, whereas females are more likely to go indoors or move to sunshine/shade.
\end{abstract}

Keywords: Thermal comfort, Gender, Pedestrian street, Severe cold region

2020 Building and Environment

Date Received: 22 July 2019 Date Accepted: 18 October 2019

Available online: 21 October 2019 


\section{Introduction}

With global warming and the rising demand for comfort levels [1], the comfort level of outdoor spaces is particularly important. People's thermal comfort in outdoor spaces is impacted by many elements. Of these, meteorological elements, such as temperature, humidity, wind speed, and solar radiation, are relatively significant affecting factors. Outdoor thermal comfort is also affected by some non-meteorological factors, including adaptation, thermal preference, gender, season, and time of day [2]. Of these factors, gender is relatively important. Previous studies indicate that, compared with males, females are more sensitive to deviations from the optimal state in the thermal environment [2-5], demonstrating that gender can impact individual thermal comfort.

A great number of studies have investigated differences between the genders with respect to thermal comfort indoors [6]. At the start of the 21st century, research on outdoor spaces began, with study sites including temperate, tropical, and Mediterranean regions. In the temperate Hungary, Kantor and Unger studied the gender distribution of specimens along different physiological equivalent temperature (PET) scales. Under conditions of gradual warming, the proportion of male samples showed a slight decline, indicating that females feel warmer in the same environment [7]. At the same time, a study by Yang et al. carried out in northern Sweden found that, compared with males, females have a higher thermal sensation vote (TSV) at higher dry-bulb temperatures and a lower TSV at lower dry-bulb temperatures. This demonstrates that females are more susceptible to variations in outdoor dry-bulb temperature, particularly when the dry-bulb temperature is higher [8]. Lam et al. produced similar results in Melbourne where a subtropical climate and temperate climate intersect. When the temperature was between 24.2 and $40.6{ }^{\circ} \mathrm{C}$, females usually felt hotter than males. When temperatures were higher than $24.2^{\circ} \mathrm{C}$, females' actual sensation vote (ASV) was remarkably higher than that of males. Moreover, females began to feel warm $\left(\mathrm{ASV}=2\right.$ ) at a temperature of $28.4-32.4{ }^{\circ} \mathrm{C}$, whereas males began to feel warm at a temperature of $32.5-36.5^{\circ} \mathrm{C}$ [9]. In Taiwan, the upper limit value of the acceptable thermal range for females $\left(28.8^{\circ} \mathrm{C} \mathrm{PET}\right)$ is lower than that for males $\left(33.2^{\circ} \mathrm{C}\right.$ $\mathrm{PET}$ ), showing that females' psychological tolerance of thermal environments is lower than that of males [10]. In tropical coastal areas, there was no obvious difference in thermal sensation and thermal acceptability between the genders; however, there is a significant gender difference in thermal preference: compared with males $(0.11)$, females $(0.17)$ prefer feeling slightly cooler [11].

In the Mediterranean climate zone, there is no prominent connection between thermal sensation and gender [12]. However, in this climate zone, scholars have carried out many studies on people's satisfaction with outdoor wind. In Portugal, for example, a very strong correlation was found between gender and wind satisfaction [3]. Oliveira and Andrade discovered that, when $32 \%$ of females expressed discomfort with wind speed, only $24 \%$ of males did so. Moreover, $44 \%$ of females said that wind speed was the most uncomfortable of all the weather elements, while only $21 \%$ of males felt the same. An increase in wind speed value also resulted in a rapid decrease in the ratio of females who felt comfortable with the wind speed, while the ratio of males fell only slightly. When the wind speed was higher than $3.7 \mathrm{~m}$ per second $(\mathrm{m} / \mathrm{s})$, more than $50 \%$ of females felt uncomfortable, compared to only $27 \%$ of males. This indicates that females are more sensitive to wind speed than males, and males feel comfortable in a wider wind speed range [3]. Andrade et al. obtained the same results as Lisbon: that is, that a significant difference in wind perception exists between the genders. Females have a lower comfort threshold with respect to wind, and this is more distinct when the wind speed is high [13]. Rutty and Scott, who researched outdoor wind perceptions in the 
tropics, found no outstanding discrepancy in wind perception, wind preference, and wind acceptability between the genders [11]. In a study on sun preference in Taiwan, Tung et al. found that the ratio of females wishing for decreased sunshine was higher when compared to the males [10].

The above review shows that current studies on gender differences in outdoor thermal comfort mainly focus on comparing the thermal comfort levels of males and females in the same thermal conditions, including thermal sensation, acceptable thermal range, thermal preference, wind satisfaction, and sun preference. However, these studies have mainly focused on hot or mild climates, not on low-temperature environments. Hence, this study aims to study gender-related thermal comfort differences in severe cold regions, with three specific goals: (1) to compare the thermal comfort levels of the genders, including thermal sensation, acceptable thermal range, and thermal preference (including wind and sun preference) and combine the results of research in other areas to conduct a comprehensive analysis; (2) to statistically analyse the factors affecting the thermal comfort of males and females and conduct a subjective survey and analysis; and (3) to compare the thermal comfort self-adjustment means, including clothing thermal resistance and activity, used by people of different genders.

\section{Materials and Methods}

\subsection{Study area}

The study was carried out in Harbin in northeast China $\left(125^{\circ} 42^{\prime}-130^{\circ} 10^{\prime} \mathrm{E}, 44^{\circ} 04^{\prime}-46^{\circ} 40^{\prime} \mathrm{N}\right.$, altitude: 132-200 m) (Fig. 1) [14, 15]. Harbin has a mid-temperate continental monsoon climate, and the mean monthly air temperature is highest in July, $\left(23.2^{\circ} \mathrm{C}\right)$ and lowest in January ($17.5^{\circ} \mathrm{C}$ ) (Fig. 2). In Building Climate Demarcation of China, Harbin is classified as a severe cold region $[16,17]$. The climate of severe cold regions is characterised by long, cold winters [18] and short, hot summers. According to the standard of QX/T 152-2012 Division of Climatic Season issued by the China Meteorological Administration, the daily average temperature is less than $10{ }^{\circ} \mathrm{C}$ in winter, higher than or equal to $22^{\circ} \mathrm{C}$ in summer, and above or equal to $10^{\circ} \mathrm{C}$ and less than $22{ }^{\circ} \mathrm{C}$ in spring and autumn. On the basis of this criterion, late June and early August are categorised as summer periods, since the mean temperature of June and August is very near $22{ }^{\circ} \mathrm{C}\left(21.17^{\circ} \mathrm{C}\right.$ and $21.33^{\circ} \mathrm{C}$, respectively). Since the mean temperature in April is very close to $10^{\circ} \mathrm{C}\left(8.17^{\circ} \mathrm{C}\right)$, late April is classified as spring. Winter in Harbin stretches from October to early April of the next year; summer is late June, July, and early August; spring is late April, May, and early June; and autumn is late August and September. Spring and autumn are known as the 'transition seasons' between summer and winter, winter is the 'cold season', and summer is the 'hot season'. Since this research is mainly aimed at cold environments, this study focuses on the cold and transition seasons.

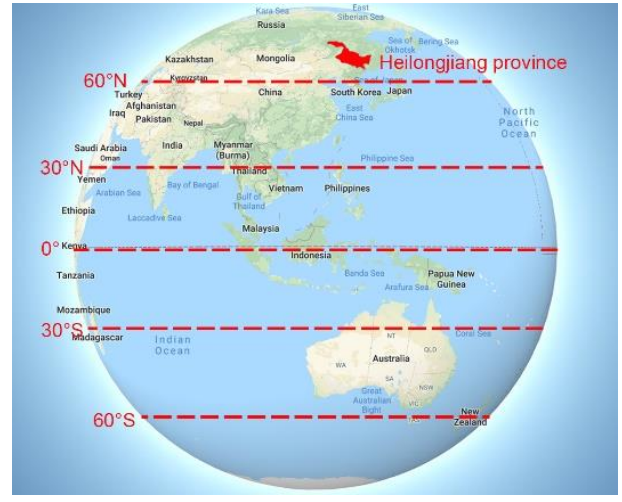

(a) Location of Heilongjiang Province

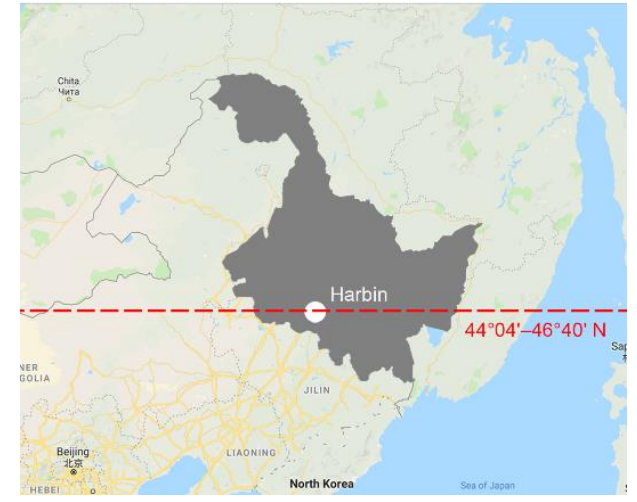

(b) Location of Harbin 
Fig. 1. Location of Harbin in Heilongjiang Province (Blue represents the ocean, and yellow and green represent the land. Image taken from the following source: Google Map); (a) Location of Heilongjiang Province; (b) Location of Harbin. (For interpretation of the references to colour in this figure legend, the reader is referred to the Web version of this article.)

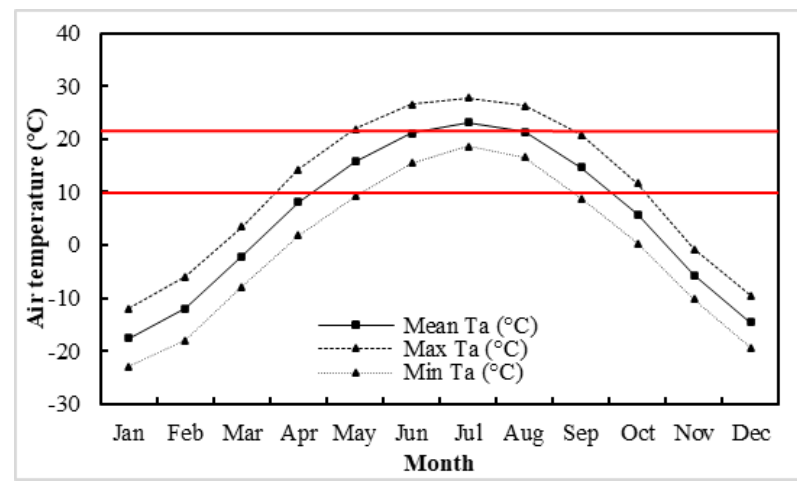

Fig. 2. Changes in average monthly air temperature in Harbin from 1988 to 2010 (the red line is the standard line of the Division of Climatic Seasons). (For interpretation of the references to colour in this figure legend, the reader is referred to the Web version of this article.)

This study analysed thermal comfort on outdoor pedestrian streets in severe cold regions, with the central avenue and Majiagou River pedestrian street being chosen as survey sites. For the central avenue, which is around $1450 \mathrm{~m}$ long, two study areas were selected, one in the southern half of the street and one in the northern half. For the Majiagou River pedestrian street, which is $1.1 \mathrm{~km}$ long, the river section passing through the children's park was selected as the research area (Fig. 3). The selected research sites span various ambient conditions: the southern part of the central avenue, which is oriented north-south and east- west and about $20 \mathrm{~m}$ wide, is partially shaded by trees; the northern part of the central avenue, which is also oriented north-south and east-west and about $50 \mathrm{~m}$ wide, has no tree cover and is about 270 $\mathrm{m}$ from the Songhua River. The Majiagou River pedestrian street is $50^{\circ}$ east of the north, with no buildings on either side. The section under study is entirely shaded by trees and is close to the Majiagou River.

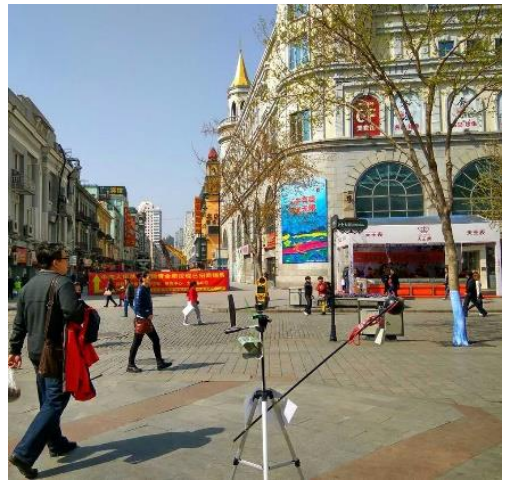

(a) Harbin central avenue (southern part)

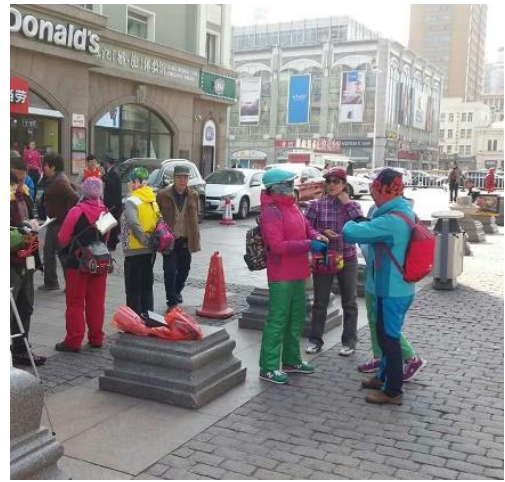

(b) Harbin central avenue (northern part)

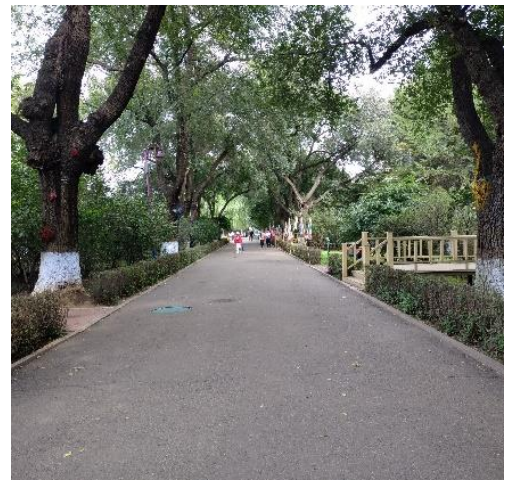

(c) Majiagou River pedestrian street

Fig. 3. Study area; (a) Harbin central avenue (southern part); (b) Harbin central avenue (northern part); (c) Majiagou River pedestrian street.

\subsection{Physical measurements}

In the process of measuring the thermal environment, the air temperature, relative humidity, and globe temperature were recorded using a BES-02 temperature and humidity recorder 
(temperature measurement range: $-30.0-50.0{ }^{\circ} \mathrm{C}$, measurement accuracy: $\leqslant 0.5{ }^{\circ} \mathrm{C}$, relative humidity $(\mathrm{RH})$ measurement range: $0.0 \%-99.0 \% \mathrm{RH}$, measuring accuracy: $\leqslant 3.0 \% \mathrm{RH})$. The globe temperature was measured by the diameter of $0.08 \mathrm{~m}$ matte-black paint spheres (reflectivity 0.95). The BES-02 temperature and humidity recorder was hung in the air in a highreflectivity aluminium box that allows natural draughts and resists solar irradiation. Wind velocity was collected with a Kestrel 5500 weather meter (wind speed measurement range: $0.4-40.0 \mathrm{~m} / \mathrm{s}$, accuracy: $\pm 3.0 \%$ ). All apparatuses were set up in accordance with the ISO 7726 standard [19] and supported by a tripod at a height of around $1.1 \mathrm{~m}$ (Fig. 4). Solar radiation was surveyed using an SM206 handheld solar power meter (solar radiation measurement range: $1-3999 \mathrm{~W}$ per square $\mathrm{m}\left[\mathrm{W} / \mathrm{m}^{2}\right]$, accuracy: $\left.\pm 5.0 \%\right)$, and the data were recorded in the questionnaire survey.

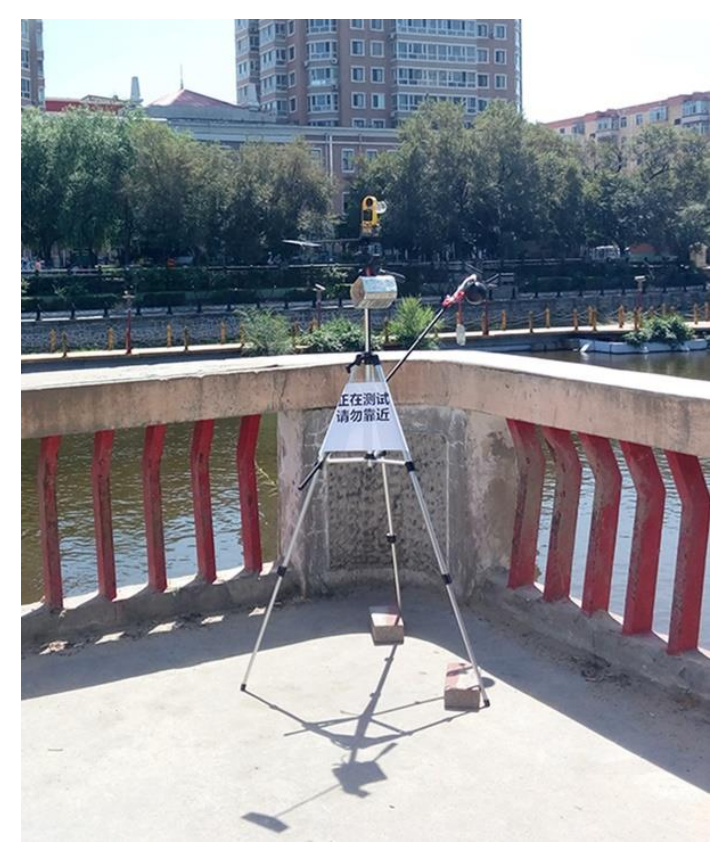

Fig. 4. Measuring instrument

\subsection{Questionnaire surveys}

The design of the thermal comfort questionnaire referred to current studies, and it was divided into two sections: basic information and a thermal comfort survey [20-23]. The basic information section covered gender, age, clothing, activity status, and so on; the thermal comfort survey section covered thermal acceptability, thermal comfort, thermal sensation, and thermal preference. Thermal acceptability was surveyed according to a 4-point scale: completely acceptable, acceptable, unacceptable, and completely unacceptable. (This paper used a 4-point scale instead of a 'yes-no' question in the survey in order to identify more acceptance levels. In 'yes-no' questioning, only two results can be obtained-acceptable and unacceptable; the 4-point scale adds two options-completely acceptable and completely unacceptable-in order to represent a deeper level of acceptability and unacceptability). Thermal sensation was measured by a 7-point scale: cold, cool, slightly cool, neutral, slightly warm, warm, and hot. Thermal preference (including temperature, wind, and sun) was measured by a 3-point scale: colder, no change, and hotter (smaller, no change, and larger and weakening, no change, and strengthening). The overall thermal comfort (OTC) was measured by a 7-point scale: very uncomfortable, uncomfortable, just uncomfortable, neutral, just comfortable, comfortable, and very comfortable. Finally, the respondents were asked which 
thermal environment elements affected them the most, and what means they wished to take to enhance their thermal comfort.

\subsection{Thermal comfort index}

There are currently many indexes that measure outdoor thermal comfort, including predicted mean vote $(\mathrm{PMV})$, effective temperature $\left(E T^{*}\right)$, standard effective temperature $\left(\mathrm{SET}{ }^{*}\right)$, and outdoor standard effective temperature (OUT_SET *). This paper uses the universal thermal climate index (UTCI) as the thermal comfort index in order to assess the thermal environment, as this index can show the real environment in which people generate the same physiological reaction as in an equivalent environmental temperature $\left({ }^{\circ} \mathrm{C}\right)$ [24]. A multi-node model based on human body temperature regulation is applied to calculate the human physiological response to the meteorological environment [25], and the 'clothing model' is also considered. Moreover, the study by Brode et al. demonstrates that the UTCI seems to suit both males and females [26]. Current research also indicates that the UTCI can be adopted in severe cold regions [27], thus indicating that it is applicable in this research. UTCI-A002 software was used to calculate the UTCI (URL: http://utci.org/utci_doku.php). This index integrates air temperature, relative humidity, wind speed, and mean radiation temperature. When these 4 environmental parameters were input into the software, it yielded the corresponding UTCI result.

Since the wind velocity was measured at a height of $1.1 \mathrm{~m}$ during the study, a conversion Formula (1) was applied to convert this into wind speed at a height of $10 \mathrm{~m}$, as required by the UTCl. The measured height is $x(\mathrm{~m})$, the measured wind speed is $v a_{x m}(\mathrm{~m} / \mathrm{s})$, and the converted wind speed is $v a(\mathrm{~m} / \mathrm{s})$ [28]. The mean radiation temperature was calculated according to the forced convection Formula (2) in the ISO 7726 standard. In this study, the reflectivity of the black sphere was 0.95 , and the diameter of the black sphere was $0.08 \mathrm{~m}$.

$v a=v a_{x m} \cdot \operatorname{LOG}(10 / 0.01) / \operatorname{LOG}(x / 0.01)$

$T_{M R T}=\left[\left(t_{g}+273\right)^{4} \frac{1.1 \cdot 10^{8} \cdot v_{a}^{0.6}}{\varepsilon_{g} \cdot D^{0.4}}\left(t_{g}-t_{a}\right)\right]^{1 / 4}-273$

where $\mathrm{T}_{\mathrm{MRT}}$ is the mean radiant temperature $\left({ }^{\circ} \mathrm{C}\right), \mathrm{t}_{\mathrm{g}}$ is the globe temperature $\left({ }^{\circ} \mathrm{C}\right), \mathrm{v}_{\mathrm{a}}$ is the air velocity $(\mathrm{m} / \mathrm{s}), t_{a}$ is the air temperature $\left({ }^{\circ} \mathrm{C}\right), \varepsilon_{\mathrm{g}}$ is the emissivity of the black globe, and $D$ is the diameter of the globe $(\mathrm{m})$.

Based on the UTCI, the TSV of people with different traits in the same thermal environment can be compared, and the neutral temperature and acceptable thermal range can also be determined. First, data are grouped into a temperature interval (bin), each spanning $2{ }^{\circ} \mathrm{C} \mathrm{UTCl}$. When comparing TSVs, the mean thermal sensation vote (MTSV) of each group is calculated first, the MTSV and UTCI are suited by linear regression, and the linear regression curves and formulas of different populations can be compared. The neutral temperature is determined by inputting $\mathrm{MTSV}=0$ into the formula, and the corresponding $\mathrm{UTCl}$ value is the neutral temperature [20]. The acceptable thermal range is acquired by counting the ratio of people in each temperature interval (bin) that are thermal unacceptable and then conducting the linear fitting. According to the regulations of the American Society of Heating, Refrigerating and AirConditioning Engineers [29], when the vast majority of people ( $\geqslant 80 \%$ ) feel that the existing thermal environment is acceptable, and only a small number of people $(\leqslant 20 \%)$ find it unacceptable, this means that the current thermal environment is receivable by this group, and 
the UTCI range corresponding to the unacceptable percentage of less than $20 \%$ is the acceptable thermal range.

\subsection{Field survey procedures}

The surveys were conducted in January, April, and September of 2017 along the central avenue and in December of 2017 and May and September of 2018 along the Majiagou River pedestrian street. The surveys were conducted once a month, yielding a total of six surveys, one per region and per season. Data obtained in January or December represented the 'cold season', and data obtained in April, May, and September represented the 'transition seasons'. Each survey lasted for one day. During the 'cold season' and 'transition seasons', respectively, the average air temperature on the test day was $-13.02{ }^{\circ} \mathrm{C}$ and $18.98{ }^{\circ} \mathrm{C}$, average relative humidity was $58.60 \% \mathrm{RH}$ and $36.17 \% \mathrm{RH}$, average wind speed was $0.89 \mathrm{~m} / \mathrm{s}$ and $0.99 \mathrm{~m} / \mathrm{s}$, and average globe temperature was $-11.50^{\circ} \mathrm{C}$ and $22.20^{\circ} \mathrm{C}$. The average values of the thermal environment parameters of two test days in different years in the same season are similar-at 9:00-16:59_ and the difference in the average air temperature was $0.44-1.89{ }^{\circ} \mathrm{C}$; the difference in the average relative humidity was $5.98-12.72 \% \mathrm{RH}$, the difference in the average wind speed was $0.10-0.61 \mathrm{~m} / \mathrm{s}$, and the difference in the average globe temperature was $0.13-4.93{ }^{\circ} \mathrm{C}$. This shows that the data are relatively significant. As the number of pedestrians was the highest from 9:00 to 16:00, data were gathered during this period. For this test, the device tripod was set up as shown in Fig. 4. The parameters measured include air temperature, relative humidity, globe temperature, and wind speed. A thermal comfort investigation of pedestrians passing by the measuring instrument was carried out. To represent the traits of the crowd in a specific space, interviewees were chosen randomly for the purposes of the survey. For the analysis of gender and thermal comfort, around 300-600 specimens (an average of 400) were collected every quarter [2, 11-13]. Hence, a total of 1225 valid samples were collected for this study. Based on the sample size, 95 times out of 100, the reported percentages can be interpreted as being accurate to within $\pm 3 \%$ [11] .

\section{Results and discussion}

\subsection{Gender differences in thermal comfort level}

\subsubsection{Thermal sensation votes}

A common way of assessing the thermal comfort level of a specific crowd is to ask pedestrians to provide a TSV. To compare the TSVs of the genders, the MTSV and UTCI of males and females were fitted by linear regression according to the method outlined in Section 2.4; these analysis results are displayed in Fig. 5. The fitted linear equations were as follows:

Cold season/male: $M T S V=0.0403$ UTCI- $0.6301\left(R^{2}=0.5674\right)($ sample size: 211$)$

Cold season/female: $M T S V=0.0439$ UTCI $0.6371\left(R^{2}=0.6714\right)($ sample size: 198$)$

Transition season/male: $M T S V=0.0557$ UTCI $-1.1023\left(R^{2}=0.6339\right)($ sample size: 306$)$

Transition season/female: $M T S V=0.0518$ UTCI $-1.2010\left(R^{2}=0.7584\right)$ (sample size: 227$)$

The fitting results showed that (Fig. 5), compared to males, the female MTSV was lower under the same UTCI, thus illustrating that females felt colder in the same thermal environment. Based on the fitting formula, the neutral temperature (that is, the temperature that the crowd 
feels is neither cold nor hot) can be counted, and it is considered the most valid index to evaluate the thermal comfort of a specific crowd. Based on the method outlined in Section 2.4, the neutral temperature of males and females in the transition seasons was thus determined by inputting MTSV = 0 into formulas (5) and (6). This revealed that the neutral temperature of males was $19.8^{\circ} \mathrm{C} \mathrm{UTCl}$, while that of females was higher at $23.2{ }^{\circ} \mathrm{C} \mathrm{UTCl}$. In the cold season, since the temperature is very low, the thermal sensation of people when out of doors is always in the range of slightly cool-cool (-1--2), and it never reaches the 'neutral' (0) level, meaning that there is no neutral temperature.

This study revealed that, at the low temperature conditions involved in this research $(-20.3-$ $25.8^{\circ} \mathrm{C}$ ), the TSV of females in the same thermal environment was lower than that of males, thus demonstrating that females felt colder under the same UTCI range. Other relevant studies have found that, in the high-temperature environment of Melbourne $\left(11.7-41.0^{\circ} \mathrm{C}\right)$, the TSV of females in the same environment was higher, thus indicating that the females were more intolerant of high-temperature environments [9]. In a moderate-temperature environment in northern Sweden $\left(12.0-26.6{ }^{\circ} \mathrm{C}\right)$, the TSV of females was higher when the dry-bulb temperature was high and lower when the dry-bulb temperature was low [8]. Research in southern Brazil also showed that females felt cooler in cold conditions and hotter in warm conditions [30]. These results demonstrated that females were less tolerant of extreme environments than males in both high- and low-temperature environments.

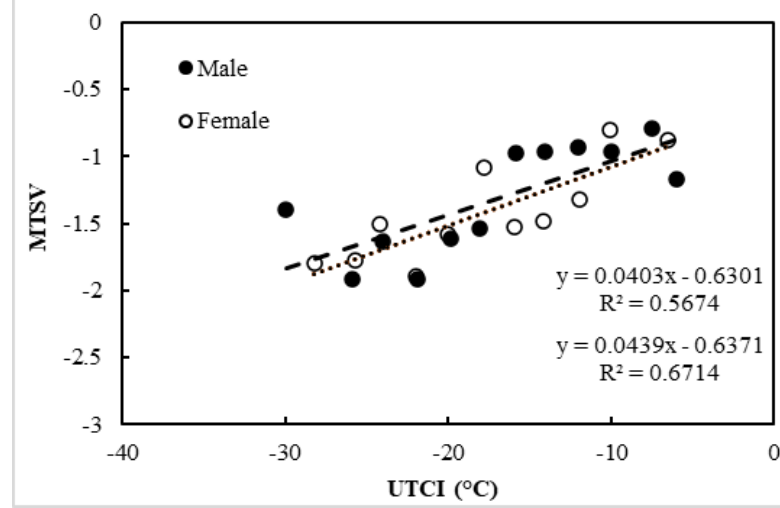

(a) Cold season

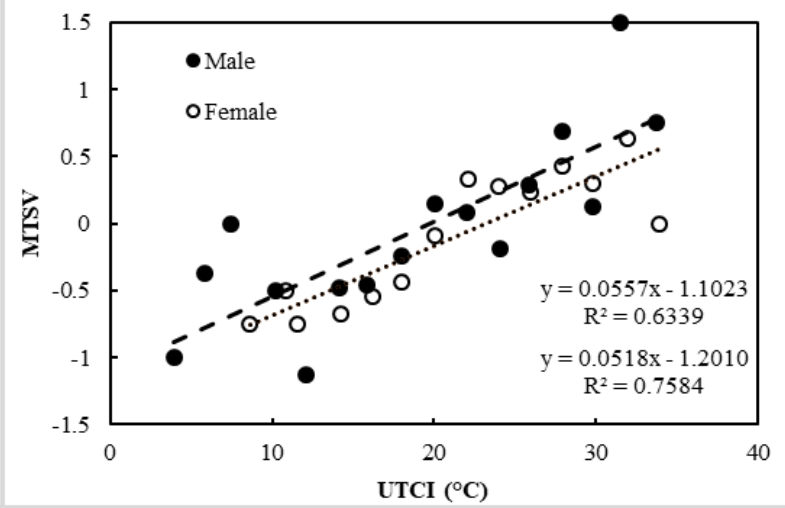

(b) Transition seasons

Fig. 5. Linear fitting lines of MTSV and UTCI (Average sample size for each data set: 17.77); (a) Cold season; (b) Transition seasons

\subsubsection{Acceptable thermal range}

Another way to assess the thermal comfort level of a certain group is to define the range of temperatures that the group feels is acceptable for the thermal environment, as described in Section 2.4. Quadratic regression fitting was performed for the UTCI and for the proportion of the population of males and females who found the temperature unacceptable. As shown in Fig. 6, the fitting formulas were as follows:

Cold season/male: $y=0.0016 x^{2}+0.0375 x+0.3987\left(R^{2}=0.4154\right)$

Cold season/female: $y=0.0012 x^{2}+0.0272 x+0.3617\left(R^{2}=0.5543\right)$

In the cold season, males and females reported similar levels of thermal acceptability. However, the thermal acceptable ratio of males above $80 \%$ ranged from $-15.34{ }^{\circ} \mathrm{C}$ to $-8.09{ }^{\circ} \mathrm{C} \mathrm{UTCl}$, whereas the thermal acceptable ratio of females was always lower than $80 \%$ and only neared $80 \%(79.24 \%)$ at a temperature of $-11.33^{\circ} \mathrm{C}$ UTCl. This indicated that, in cold season, females 
never found the outdoor thermal environment acceptable, thus showing that females were more intolerant of low temperatures. Moreover, the data indicated that the temperature that was acceptable to outdoor people in the cold season was very low. Because of the influence of thermal experience, the residents living in cold areas showed a strong adaptability to the cold season. Thus, when the cold season arrived, they also had more accurate expectations regarding low temperatures and tended to adjust their clothes and activities according to these expectations. The questionnaire survey process showed that many residents in cold areas believed that 'the winter was originally so cold, and it is a natural state of seasonal change'. This idea also improved their psychological acceptance of low temperature environments to a certain extent. In the transition seasons, nearly $100 \%$ of people of both genders accepted the existing thermal environment, meaning that males and females found the temperature equally acceptable.

The above analysis demonstrates that females reported a narrower range of thermal acceptability in severe cold regions. Moreover, other related studies have shown that the upper limit of acceptable temperature as reported by females in Taiwan was $28.8^{\circ} \mathrm{C}$ PET, which is lower than that of males $\left(33.2^{\circ} \mathrm{C}\right.$ PET) [10]. Amindeldar et al. also showed that females had narrower ranges of comfort in colder circumstances $\left(8-16^{\circ} \mathrm{C}\right)$ [31], thus demonstrating that females also reported lower levels of thermal acceptability than males in other environmental conditions.

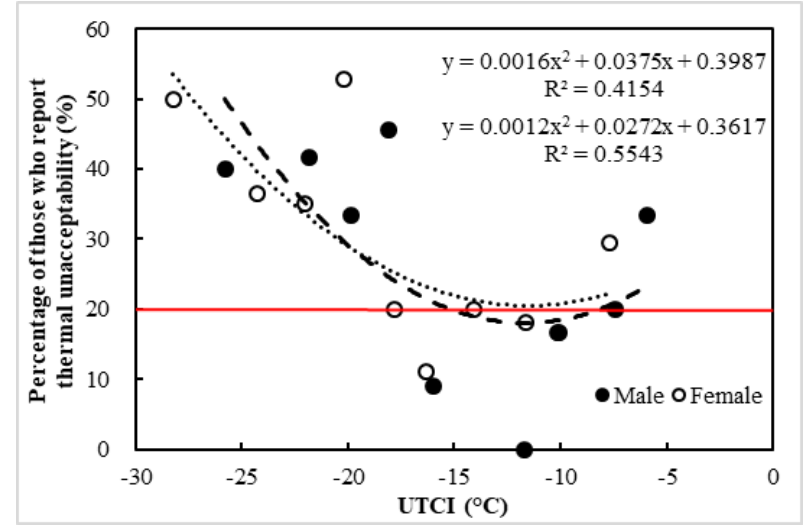

Fig. 6. Acceptable thermal range (cold season) (Average sample size for each data set: 16.66)

\subsubsection{Thermal preference votes}

It has been noted above that humans' thermal comfort in outdoor spaces is impacted by many factors. To determine the comfort level of a crowd based on a single meteorological factor, this study investigated the differences in the distribution patterns of temperature, wind speed, and sun preference between the genders based on OTC [10]. As noted in Section 2.3, OTC is divided into 7 grades. For the sake of convenience, in this study, OTC was divided into 3 grades. The uncomfortable grades $(-3,-2$, and -1$)$ were classified as dissatisfied, and the comfortable grades $(1,2$, and 3$)$ were classified as satisfied. The neutral grades remained unchanged. Since most people feel neutral and dissatisfied in the cold season and neutral and satisfied in the transition seasons, the cold and transition seasons were combined for the purpose of analysis. Temperature, wind, and sun preference were rated on the 3-point scale described in Section 2.3.

As shown in Fig. 7, when people were satisfied with the thermal environment, a smaller ratio of them had certain preferences regarding the temperature, wind, and sunshine. When people gradually became dissatisfied, moving from satisfied to neutral to dissatisfied, the proportion of 
those with a preference for temperature, wind, and sunshine gradually increased. Therefore, it can be said that people have different expectations in different thermal environments. In the cold and transition seasons in severe cold regions, people out of doors mainly preferred higher temperatures, lower wind speeds, and stronger sunshine.

Clear gender differences were discernible in preferences regarding the thermal environment on the part of people who were outside. In terms of temperature preferences (Fig. 7(a)), in the low temperature conditions under study $\left(-20.3-25.8^{\circ} \mathrm{C}\right)$, females preferred higher temperatures compared to males. In each OTC group, the ratio of people who preferred higher temperatures was higher for females than for males; the gender differences in the dissatisfied, neutral, and satisfied OTC groups were $8.35 \%, 5.2 \%$, and $8.83 \%$, respectively. Other related studies indicated that females preferred lower temperatures in high-temperature environments (27.0$35.1^{\circ} \mathrm{C}$ ) [11], thus demonstrating that females had higher demands with respect to temperature compared to males in any temperature conditions.

Regarding wind preference (Fig. 7(b)), when the outdoor group felt satisfied or dissatisfied with the environment, there was no gender difference in their wind speed preference. When people felt neutral, the proportion of males expecting a lower wind speed was larger than that of females (the difference was as large as 20.5\%). However, studies in other areas all showed that females were more sensitive to wind and that their comfort level with respect to wind was lower in the case of higher temperatures $\left(14.6^{\circ} \mathrm{C}-30.6^{\circ} \mathrm{C}\right)[3,13]$. This may have been related to the low-temperature environment and narrow wind speed range in Harbin or to the behavioural habits of people when out of doors.

In terms of sun preference (Fig. 7(c)), males and females preferred the same amount of sunshine. To further analyse the impact of objective physical conditions on gender differences in sun preference, the sun preferences of the genders at different solar radiation levels were compared and studied. In accordance with previous research [10], the samples were divided into groups each spanning $200 \mathrm{~W} / \mathrm{m}^{2}$. As shown in Fig. 7(d), except for the $200-400 \mathrm{~W} / \mathrm{m}^{2}$ interval, the ratio of females wanting stronger sunshine was higher than that of males. Moreover, as the strength of the sunshine gradually increased, the percentage of females wanting the sunshine to become stronger gradually decreased, and at the level of $800 \mathrm{~W} / \mathrm{m}^{2}, 11.8 \%$ of people still wanted the sunshine to increase. However, above $400 \mathrm{~W} / \mathrm{m}^{2}$, no male wanted more sunshine. In addition, other related studies showed that, in high temperature conditions, a higher ratio of females wanted the sunshine to weaken [10], showing that females were more sensitive to sunshine in both high and low temperature conditions.

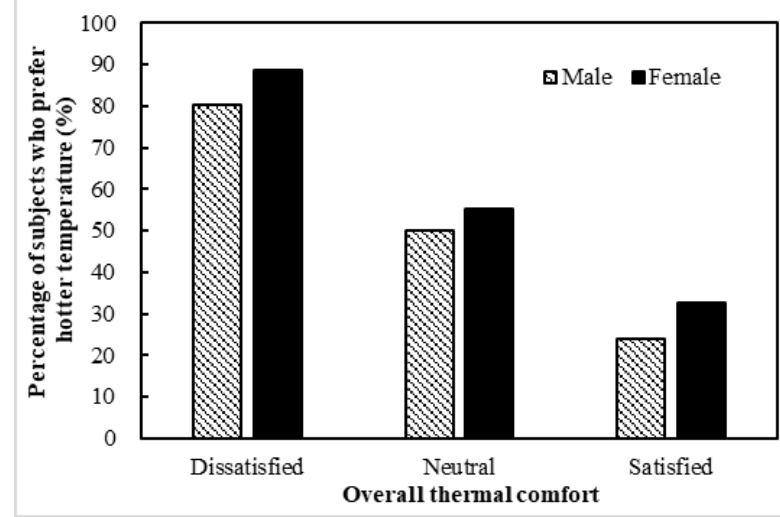

(a) Hotter temperatures (categorised by OTC state)

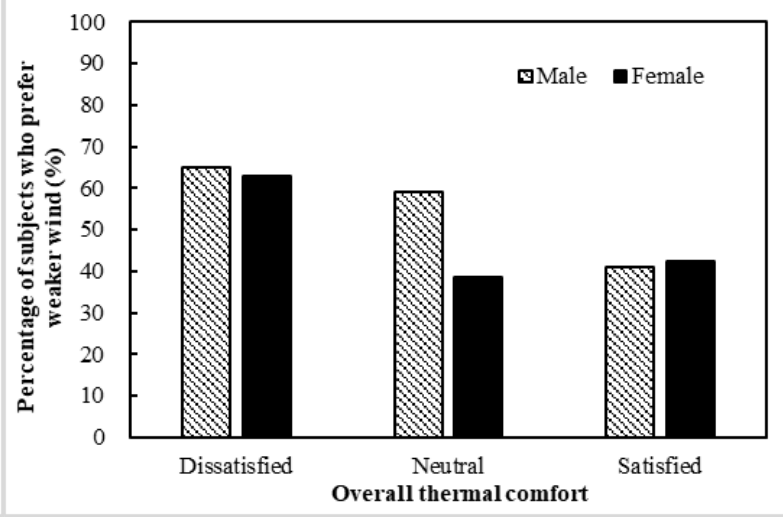

(b) Weaker wind (categorised by sunshine levels) 


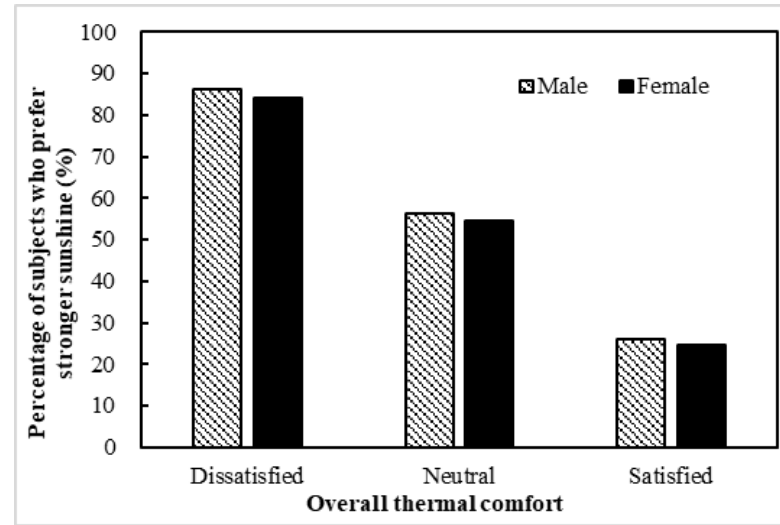

(c) Stronger sunshine (categorised by OTC state)

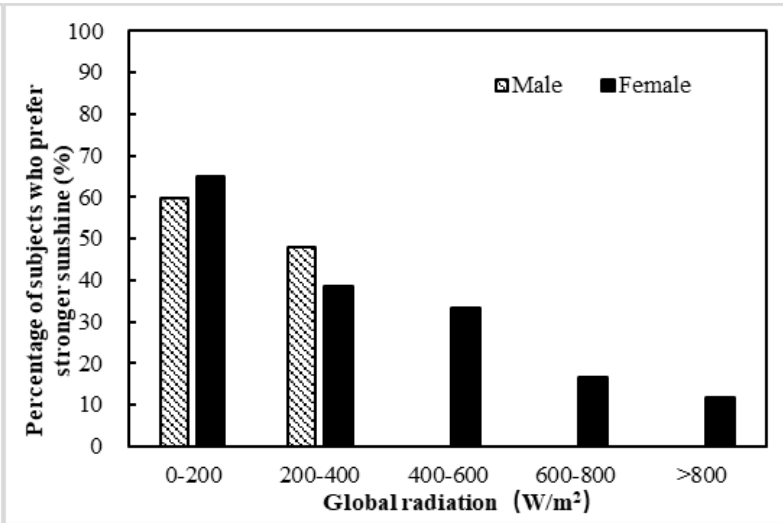

(d) Stronger sunshine (categorised by sunshine levels)

Fig. 7. Percentage of male and female subjects that preferred hotter temperatures, weaker wind, and stronger sunshine (Average sample size for each data set: 74.12); (a) Hotter temperatures (categorised by OTC state); (b) Weaker wind (categorised by OTC state); (c) Stronger sunshine (categorised by OTC state); (d) Stronger sunshine (categorised by sunshine levels)

\subsubsection{Correlations among psychological parameters}

According to these results, outdoor people's thermal sensation, thermal acceptability, thermal comfort, and thermal expectation were compared and analysed. It was found that people continued to feel 'slightly cool' and 'cool' during the cold season; however, there was an acceptable temperature range for outdoor people, which was an indication of acceptable thermal environment even though their sensation deviated from the middle state in the cold season. However, studies on the Mediterranean climate signified that thermal environments were unacceptable when people felt 'cool' or 'warm' [12,32]. This may have been due to the relatively comfortable or high temperature climate that the Mediterranean possesses (air temperature is around $7-31^{\circ} \mathrm{C}$ ). People with no experience of extreme climate conditions were more likely to experience less tolerance towards deviations from the optimal thermal environment. A comprehensive analysis of the cold season and transition seasons suggested that people still had expectations regarding the thermal environment, despite being satisfied with current thermal environment. In other words, people were able to accept the thermal environment in a relatively large temperature range yet, to reach their utmost expectations on the temperature range may be very narrow. Therefore, although outdoor people were more likely to accept different thermal environments, it was difficult to achieve the optimal state of expectation. The information mentioned in this paper is the same as the research results from Taiwan (air temperature is around $12-33^{\circ} \mathrm{C}$ ) [20].

\subsection{Gender differences in factors affecting thermal comfort}

\subsubsection{Factors affecting thermal comfort}

In order to determine the factors affecting thermal comfort, logistic regression analysis was conducted with TSV as a dependent variable and air temperature, absolute humidity, wind speed and solar radiation as the independent variables. (Since relative humidity is a function of air temperature, absolute humidity was used as an independent variable [33]). Before the regression, a collinearity diagnosis was made. It was found that there was a collinearity between air temperature and absolute humidity in the cold season, which may have been 
related to the climatic characteristics of severe cold regions. Therefore, in accordance with the experience in the existing literature, humidity was excluded in the process of cold season regression [33-35].

As shown in Tables 1 and 2, the cold season regression analysis results showed that only the significant level of air temperature was less than 0.05 , and that of other thermal environment parameters was more than 0.05 ; furthermore, the results for males and females were the same. This showed that only air temperature had an effect on outdoor thermal comfort in the cold season. This may have been due to low temperatures during the cold season in severe cold areas. Within the realisable range, humans always feel cold, regardless of the wind and sunshine, thus lowering humans' sensitivity to thermal environment factors other than temperature. In the transition seasons, the significant level of air temperature and solar radiation was less than 0.05 , and the results for males and females were the same. It has been stated that only air temperature and solar radiation can have any impact on thermal comfort in the transition seasons. However, the analysis results under hotter conditions showed other parameters, such as wind speed, which can also have some influence on thermal comfort [3336]. Combining the results of the cold season research, it can be inferred that when the temperature is lower, the outdoor people are less sensitive to other thermal environment parameters besides air temperature. When the temperature is closer to the comfortable state, the influence of other thermal environment parameters on thermal comfort is greater, and a greater number of parameters that affect thermal comfort will be present.

Table 1

Results of the logistic regression analysis (male)

\begin{tabular}{|c|c|c|c|c|c|}
\hline Model & Evaluation & Standard error & Wald & Degree of freedom & Significant level \\
\hline \multicolumn{6}{|l|}{ Cold season } \\
\hline Air temperature & 0.218 & 0.035 & 38.491 & 1 & 0.000 \\
\hline Solar radiation & 0.001 & 0.002 & 0.277 & 1 & 0.599 \\
\hline Wind speed & 0.016 & 0.242 & 0.004 & 1 & 0.948 \\
\hline \multicolumn{6}{|l|}{ Transition seasons } \\
\hline Air temperature & 0.442 & 0.139 & 10.056 & 1 & 0.002 \\
\hline Solar radiation & 0.003 & 0.001 & 5.561 & 1 & 0.018 \\
\hline Wind speed & -0.205 & 0.313 & 0.428 & 1 & 0.513 \\
\hline Absolute humidity & -0.308 & 0.245 & 1.582 & 1 & 0.208 \\
\hline
\end{tabular}

Table 2

Results of the logistic regression analysis (female)

\begin{tabular}{|c|c|c|c|c|c|}
\hline Model & Evaluation & Standard error & Wald & Degree of freedom & Significant level \\
\hline Cold season & & & & & \\
\hline Air temperature & 0.111 & 0.030 & 14.055 & 1 & 0.000 \\
\hline
\end{tabular}



doi: 10.1016/j.buildenv.2019.106488

$\begin{array}{cccccc}\text { Solar radiation } & 0.001 & 0.002 & 0.653 & 1 & 0.419 \\ \text { Wind speed } & -0.147 & 0.212 & 0.483 & 1 & 0.487\end{array}$

Transition seasons

\begin{tabular}{|c|c|c|c|c|c|}
\hline Air temperature & 0.223 & 0.109 & 4.191 & 1 & 0.041 \\
\hline Solar radiation & 0.003 & 0.001 & 15.974 & 1 & 0.000 \\
\hline Wind speed & -0.368 & 0.286 & 1.657 & 1 & 0.198 \\
\hline Absolute humidity & -0.118 & 0.202 & 0.343 & 1 & 0.558 \\
\hline
\end{tabular}

\subsubsection{Subjective views of factors affecting thermal comfort}

Regarding the factors impacting thermal comfort, the subjective views of pedestrians were elicited in the investigation by using questions such as 'which factor most affects your current state of thermal comfort?' As shown in Fig. 8, the results showed that, in the cold season, pedestrians felt that their thermal comfort was most impacted by temperature, followed by sunshine and wind. Compared to males, a higher percentage of females felt that temperature most impacted their thermal comfort, and a lower percentage felt that sunshine most impacted their thermal comfort. In the transition seasons, people usually felt that sunshine and temperature affected their thermal comfort the most, followed by wind speed. Females felt that sunshine affected their thermal comfort the most, while males felt that temperature affected their thermal comfort the most. Therefore, in the cold and transition seasons, temperature and sunshine were considered the most influential factors with respect to thermal comfort, followed by wind speed. This is basically consistent with the results reported in Section 3.2.1. However, in the analysis results for females in transition season there were some deviations. Females subjectively thought that sunshine affected their comfort more, which may have been related to psychological factors, and this led to females' greater sensitivity to sunshine.

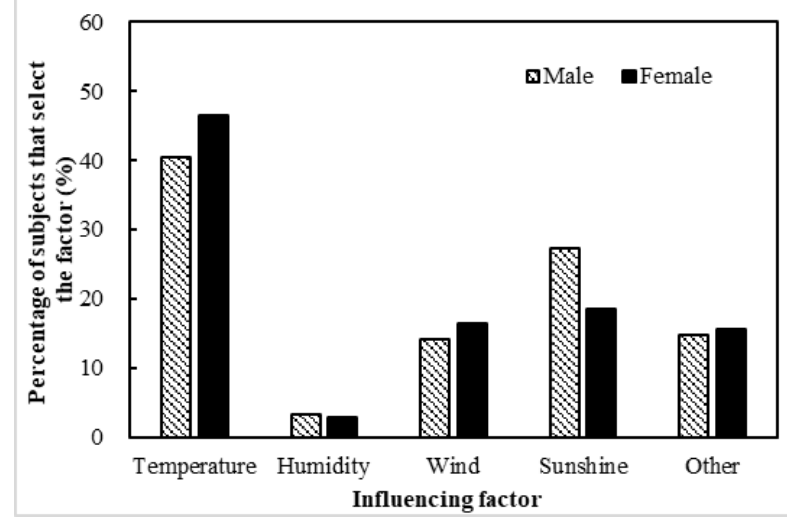

(a) Cold season

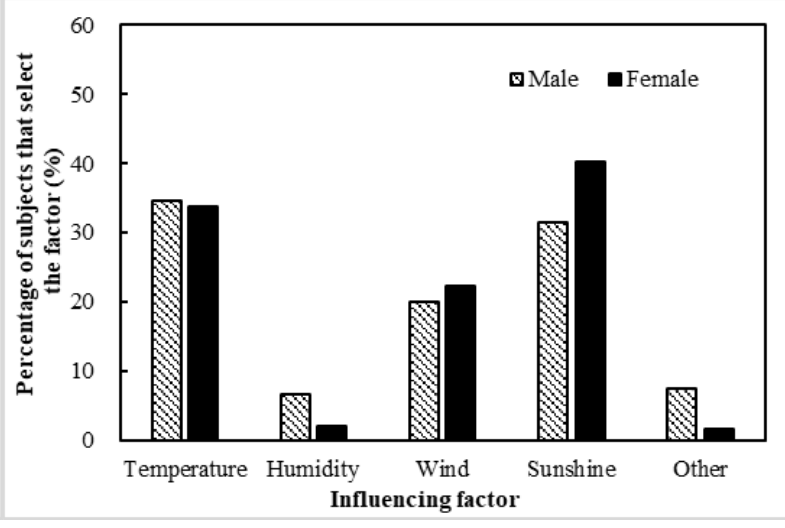

(b) Transition seasons

Fig. 8. Subjective views of the most important factor affecting thermal comfort (Average sample size for each data set: 31.95); (a) Cold season; (b) Transition seasons 


\subsection{Gender differences in thermal comfort self-regulation}

\subsubsection{Clothing thermal resistance}

The clothing thermal resistance is calculated using the method provided in ISO9920 [37]. The thermal resistance of individual garments $\left(I_{c l u}\right)$ is obtained from look-up tables, while the total clothing thermal resistance $\left(I_{c l}\right)$ is calculated according to Formula (9). Considering cold season as an example (below $0{ }^{\circ} \mathrm{C}$ ), one of the typical clothing forms is as follows: thermal undershirt ( $0.20 \mathrm{clo})$, shirt $(0.26 \mathrm{clo})$, down jacket $(0.55 \mathrm{clo})$, briefs $(0.04 \mathrm{clo})$, insulating trousers ( $0.30 \mathrm{clo}$ ), normal trousers ( $0.25 \mathrm{clo})$, boots ( $0.10 \mathrm{clo})$, socks (0.02 clo), cap ( $0.01 \mathrm{clo})$, and gloves $(0.05 \mathrm{clo})$, and the total clothing thermal resistance is calculated as 1.65 clo according to Formula (9). The average thermal resistance of every $1{ }^{\circ} \mathrm{C}$ is calculated, and the data point with the highest thermal resistance in regression fitting is extracted to obtain the Harbin's highest clothing thermal resistance, which is 1.64 clo [27].

$I_{c l}=0.161+0.835 \sum I_{c l u}$

Compared to other regions, the lowest temperatures of Finland and Harbin are similar at about $-20^{\circ} \mathrm{C}$; thus, the highest clothing thermal resistance is also around $1.65 \mathrm{clo}[27,38,39]$. However, although the lowest temperature in some areas is $15-27{ }^{\circ} \mathrm{C}$ higher than Harbin, their highest clothing thermal resistance is similar to Harbin and between 1.50 and 1.90 clo [26,40-42]. This may be because the local people in each region have adapted to the local climate and wear the thickest clothes at the lowest temperature throughout the year, according to their experience; this results in Harbin's clothing thermal resistance not being higher than that of high temperature areas. In addition, this study selected sunny days with sufficient outdoor sunshine to collect data (as Fig. 3), and Harbin's indoor heating temperature can usually reach $16-24{ }^{\circ} \mathrm{C}$, as required by the GB/T18883-2002 standard [43]; thus, pedestrians can go outside in the sun or enter roadside shops to avoid the cold at any time, which also reduces their demand for high thermal resistance clothing. To summarize, under the influence of climate, adaptability, experience, and perceived control, Harbin's clothing thermal resistance is slightly lower, but within a range that can be explained.

Section 3.1 demonstrated that gender-differentiated groups had differing thermal comfort levels and that clothing thermal resistance may have been one of the elements driving this difference. As shown in Fig. 9(a), in the cold season, the thermal resistance of females' clothing was higher than that of males' clothing; when the UTCI gradually increased, the thermal resistance of males' clothing decreased more quickly. Comparing the consequences of the acceptable thermal range described in Section 3.1.2 showed that, when the UTCI was higher than $-20^{\circ} \mathrm{C}$, females were less able to accept the current thermal environment compared to males; thus, they chose to wear more clothing to keep themselves warm. Nonetheless, females' thermal acceptability level remained lower than males', thus demonstrating that, when the UTCI was higher than $-20{ }^{\circ} \mathrm{C}$, clothing had a limited influence on thermal comfort. When the UTCI was less than $-20^{\circ} \mathrm{C}$, males' thermal unacceptability level was lower, possibly because clothing thermal resistance had a greater influence on thermal comfort when the temperature was lower. In cold conditions, males did find it colder when they wore less clothing. The t-test consequences of the thermal resistance of clothing with respect to the different genders in the cold season indicated that the thermal resistance of females' clothing was significantly higher than that of males $(t=-4.282 ; p=0.000)$. In the transition seasons (Fig. $9(b)$ ), there was no significant difference in clothing thermal resistance between the genders. Other relevant studies also demonstrated that, when the air temperature was higher $\left(3.4-41.0^{\circ} \mathrm{C}\right)$, the clothing thermal resistance of the gender groups did not differ significantly $[3,9,12,13]$. 

doi: 10.1016/j.buildenv.2019.106488

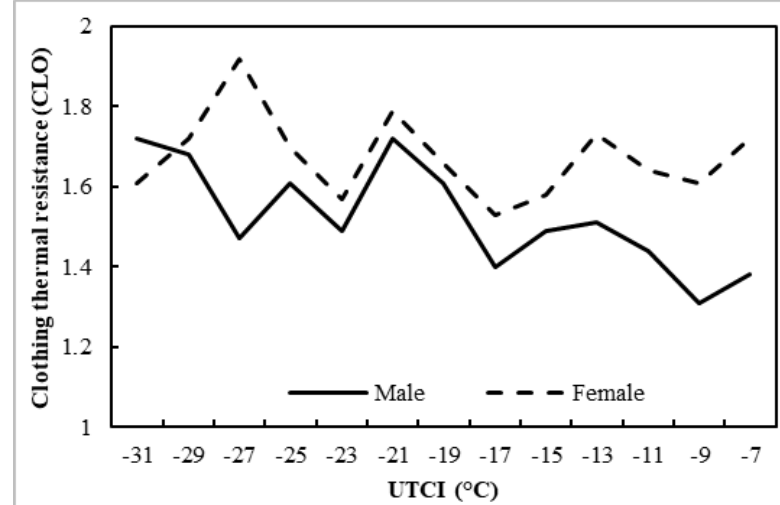

(a) Cold season

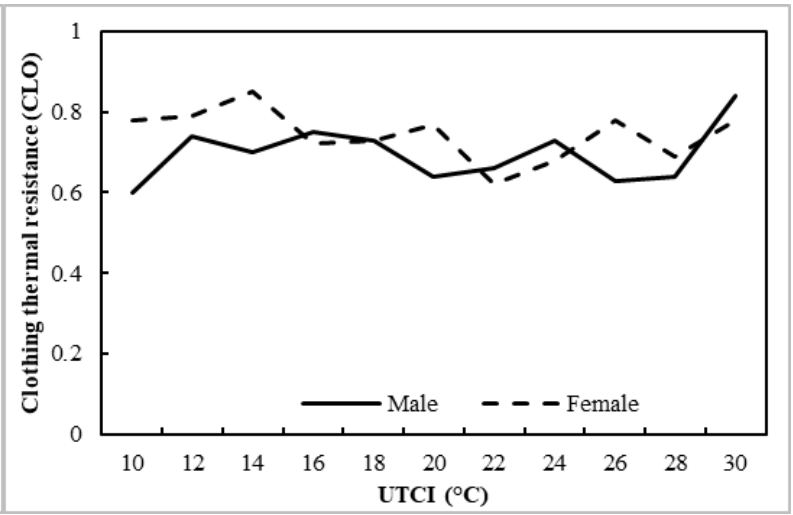

(b) Transition seasons

Fig. 9. Clothing thermal resistance (Average sample size for each data set: 17.20); (a) Cold season; (b) Transition seasons

\subsubsection{Activity status}

The activity status of people when outdoors impacted their metabolism, which then impacted their thermal comfort from a physiological standpoint. Research on outdoor exposure in winter in Finland revealed that males spent more time in a colder environment during their leisure time [44], thus indicating that there may be gender differences in levels of outdoor activity. Thus, this study recorded people's outdoor activity status before they answered the questionnaire. The survey showed that activity status mainly included four types of activity: sitting, standing, walking, and exercise. A comparison of the activity status of different gender groups (see Fig. 10) showed that a higher ratio of females engaged in sedentary activity such as sitting or standing compared to males and that this trend was even more pronounced during the transition seasons. On the other hand, a higher percentage of males walked and exercised. The results of metabolic rate calculations showed that exercise could improve metabolic rates (the metabolic rates of males for sedentary activity [sitting or standing], walking and exercising were 92, 178, and 344, respectively), and the metabolic rate for males in different activity states was higher than that of females (the metabolic rates of females for sedentary activity [sitting or standing], walking, and exercising were 83,150 , and 278, respectively) [45,46]. Males may have therefore felt hotter in the same thermal conditions, thus lowering their neutral temperature. This finding was consistent with the results of the neutral temperature study described in Section 3.1.1, and it demonstrated that activity status may have been one of the reasons for gender differences in thermal comfort levels.

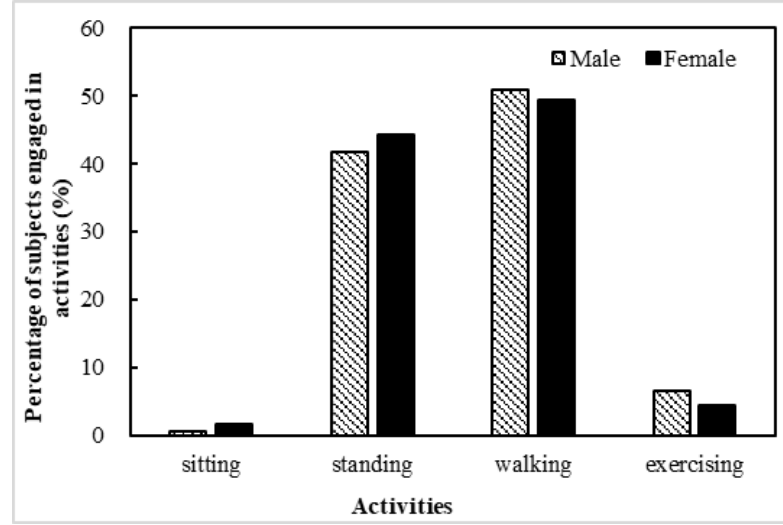

(a) Cold season

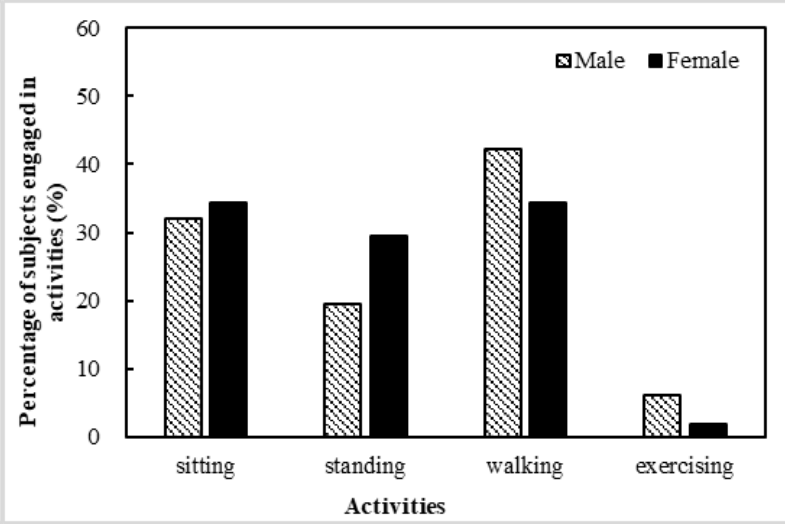

(b) Transition seasons 
Fig. 10. Percentage of subjects engaged in outdoor activities; (a) Cold season; (b) Transition seasons; (Average sample size for each data set: 33.93 )

\subsubsection{Ways to improve thermal comfort}

To improve thermal comfort outdoors, people's subjective opinions were elicited by asking them, 'How would you prefer to improve your level of thermal comfort?' As shown in Fig. 11, in the cold season, most people selected escaping the outdoor environment and going indoors to enhance their thermal comfort, followed by the desire to be in the sunshine (or shade), and doing exercises. During the transition seasons, people were most likely to seek sunshine (or shade), followed by doing exercises or going indoors. In terms of gender differences, compared with males, females preferred to go indoors and out in the sun (or move to the shade) rather than exercise. This finding corresponds to the results reported in sections 3.1.3 and 3.3.2. Females preferred stronger sunshine, while a larger number of males preferred walking and exercising.

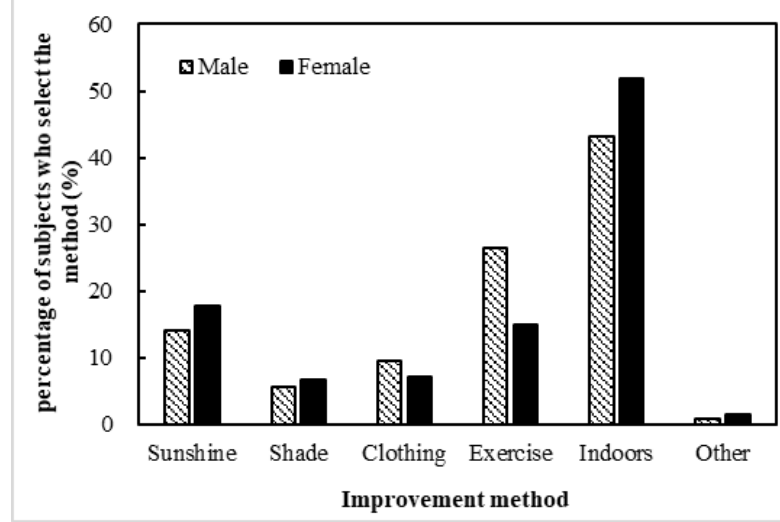

(a) Cold season

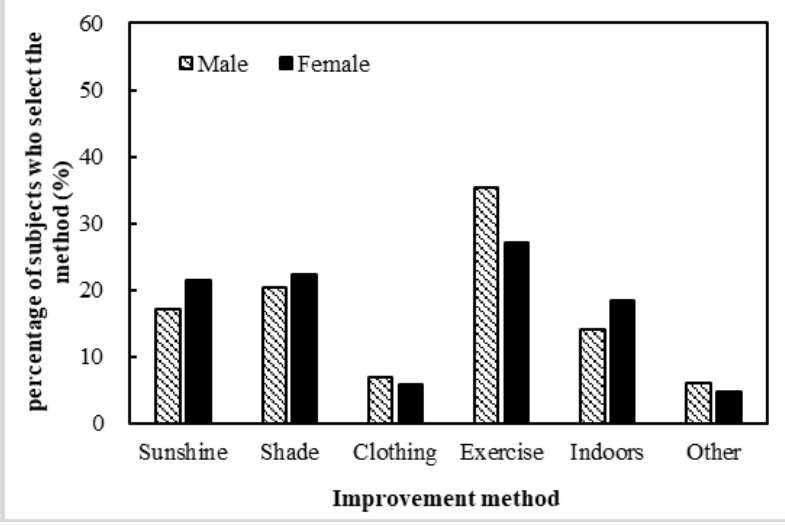

(b) Transition seasons

Fig. 11. How people prefer to improve their thermal comfort out of doors (Average sample size for each data set: 72.25); (a) Cold season; (b) Transition seasons

\subsubsection{The characteristics of thermal comfort self-regulation in severe cold regions}

By comparing outdoor people's adaptation behaviour toward cold environments in other areas [47-51], it was found that the results of this study were similar to those in other areas. However, compared with other areas, this study was conducted in places with colder climates. Therefore, there were discrepancies while comparing the results. (The lowest temperature in this study was $-20.3^{\circ} \mathrm{C}$, and the lowest temperature in the other studies was about $0{ }^{\circ} \mathrm{C}$ ). First, other studies showed that thermal comfort directly affected people's decisions regarding going outdoors. More people are likely to choose staying indoors during the cold weather rather than going outdoors, though there may be some who will opt to go outdoors regardless of the weather [47-49]. Second, people preferred sunshine and avoided the strong wind. They tended to gather in places where sunshine was plentiful, while they rarely stayed in places where sunshine was scarce, and the wind was strong [50]. Moreover, outdoor people tended to consciously or unconsciously change the clothes they wore, and their acceptance of the environment determined how many clothes they wore [47,51]. These results from previous research were similar to those of this study - that is, people choose to go indoors, look for sunshine, and modify their clothing in order to adapt to the low temperature environment (Reference sections 3.3.1 and 3.3.3). However, previous studies did not address the state of exercise. When the temperatures dropped, people only reduced their sedentary behaviour and 
chose to stand more [50]. However, in this study, when the temperature was low, almost no one sat down, opting instead to keep standing and walking (Reference section 3.3.2). Many people chose to exercise in order to improve their thermal comfort level (Reference section 3.3.3). These findings suggested that people tended to select intensive activities in order to resist low temperatures in colder environments. In addition, during the investigation, it was also observed that some people preferred to use portable heating devices in order to keep out the cold; these included warm pastes (made through the reactions of raw materials under the action of oxygen to generate heat) or electric heaters (using the principle of resistance in order to generate heat and thus release heat).

\section{Conclusions}

By means of a field survey and statistical data analysis, a thermal comfort study was carried out in Harbin, which is located in a severe cold region. The aim of the study was to determine whether there are differences in thermal comfort levels, influencing factors, and self-regulation between the genders. The main results of the study are as follows.

A comparison of thermal comfort levels shows that the value of females' MTSV was lower than males' under the same UTCI, and females' neutral temperature $\left(23.2^{\circ} \mathrm{C} \mathrm{UTCl}\right)$ in the transition seasons is higher than that of males $\left(19.8^{\circ} \mathrm{C} \mathrm{UTCI}\right)$. In the cold season, the UTCI range of males' acceptable proportion to thermal environment higher than $80 \% \mathrm{~s}-15.34-8.09{ }^{\circ} \mathrm{C}$. The percentage of females who find the thermal environment acceptable is always lower than $80 \%$, and this figure only approaches $80 \%$ when the $\mathrm{UTCl}$ is $-11.33{ }^{\circ} \mathrm{C}$. With respect to thermal preference, females expect higher temperatures than do males. In terms of wind preference, when the outdoor group felt neutral, the proportion of males expecting a lower wind speed was higher than that of females. With respect to sun preference, the proportion of females expecting stronger sunshine was higher than that of males in any solar radiation conditions $\left(0-800 \mathrm{~W} / \mathrm{m}^{2}\right)$. Regarding the factors affecting thermal comfort, the results of the study show that, in the cold season, only air temperature has an impact on thermal comfort. In the transitional seasons, air temperature and solar radiation had an impact on thermal comfort; the results were the same for both males and females. The investigation also requested the subjective opinions of pedestrians on the factors affecting thermal comfort; the results of these are basically consistent with the results of the analysis outlined above. However, in the analysis results for females in transition season there are some deviations, as females subjectively thought that sunshine affected their comfort to a greater extent.

The results of the research into thermal comfort self-regulation methods demonstrated that the thermal resistance of females' clothing is higher than that of males in the cold season, and the influence of clothing thermal resistance on thermal comfort is greater when the temperature is lower. During the transition seasons, there was hardly any difference in clothing thermal resistance between the genders. Males are more likely than females to select walking and exercise as outdoor activities, which in turn increase their metabolism and lower their neutral temperature. Hence, when choosing ways to improve thermal comfort, males are more inclined to do exercise, while females are more inclined to go indoors and into the sunshine (or shade). By summarising these results and comparing them with research results in other areas, it is found that females' tolerance of thermal environments is lower than that of males in different environmental circumstances. This is consistent with Fanger's research results [3]. This difference may be connected to heat dissipation efficiency [52,53], of which gender is a significant determinant [9]. Moreover, studies on thermal comfort self-regulation indicate that people of different genders display different behaviour patterns in clothing and activity status, 
and these can lead to different metabolic rates, thus resulting in differences in thermal comfort level. This is also why people in severe cold areas choose to be more active rather than sedentary in order to cope with the cold climate, compared to other areas.

The results of this study can be used as a reference for the design of gender-sensitive outdoor environments in regions with severe cold or areas with similar environments, also considering gender differences in other aspects [54-56]. Taking into account the higher thermal environment tolerance of males-as opposed to females-in severe cold regions, local governments and planners should pay greater attention to females' comfort and feelings in their urban public space planning and designing; this will help to improve the overall comfort of outdoor people. For example, according to the results of this study, females are more likely to prefer sunshine compared to males. Therefore, it may be more important to create areas for sunlight and reduce shadows instead of providing shelter from the wind in severe cold areas during the winter. In addition, the above research indicates that females are less interested in outdoor activities compared to males. However, the number of females choosing to go out during the milder transitional season has increased significantly. Therefore, if the thermal comfort level of females in outdoor spaces can be improved, the time and intensity of females' outdoor activities can be increased; this is beneficial to their health and can help to improve utilization efficiency for outdoor public spaces and the living standards of urban residents.

\section{Funding}

This work was supported by the National Natural Science Foundation of China [grant number 51438005].

\section{Declaration of Competing Interest}

The authors declare that they have no known competing financial interests or personal relationships that could have appeared to influence the work reported in this paper.

\section{Acknowledgements}

The authors would like to thank all respondents who participated in this study. 


\section{References}

[1]ZY Duan, XD Zhao, JM Li, Design, fabrication and performance evaluation of a compact regenerative evaporative cooler: Towards low energy cooling for buildings, Energy. 140 (2017) 506-519. doi: 10.1016/j.energy.2017.08.110.

[2]A Middel, N Selover, B Hagen, N Chhetri, Impact of shade on outdoor thermal comfort-a seasonal field study in Tempe, Arizona, Int J Biometeorol. 60 (2016) 1-13. doi: 10.1007/s00484-016-1172-5.

[3]S Oliveira, H Andrade, An initial assessment of the bioclimatic comfort in an outdoor public space in Lisbon, Int $\mathrm{J}$ Biometeorol. 52 (2007) 69-84. doi: 10.1007/s00484-007-0100-0.

[4]S Lu, H Xia, S Wei, K Fang, Y Qi, Analysis of the differences in thermal comfort between locals and tourists and genders in semi-open spaces under natural ventilation on a tropical island, Energy Build. 129 (2016) 264-273. doi: 10.1016/j.enbuild.2016.08.002.

[5]N Makaremi, E Salleh, MZ Jaafar, A Ghaffarian Hoseini, Thermal comfort conditions of shaded outdoor spaces in hot and humid climate of Malaysia, Build Environ. 48 (2012) 7-14. doi: 10.1016/j.buildenv.2011.07.024.

[6]Z Wang, DR Dear, MH Luo, et al., Individual difference in thermal comfort: A literature review, Build Environ. 138 (2018)181-193. doi: 10.1016/j.buildenv.2018.04.040.

[7]N Kántor, J Unger, Benefits and opportunities of adopting GIS in thermal comfort studies in resting places: an urban park as an example, Landsc Urban Plan. 98 (2010) 36-46. doi: 10.1016/j.landurbplan.2010.07.008.

[8]B Yang, T Olofsson, G Nair, A Kabanshi, Outdoor thermal comfort under subarctic climate of north sweden - a pilot study in umeå. Sustain. Cities Soc. 28 (2016) 387-397. doi: 10.1016/j.scs.2016.10.011.

[9]CKC Lam, M Loughnan, N Tapper, Visitors' perception of thermal comfort during extreme heat events at the royal botanic garden Melbourne, Int J Biometeorol. 62 (2016) 97-112. doi: 10.1007/s00484-015-1125-4.

[10]CH Tung, CP Chen, KT Tsai, N Kántor, RL Hwang, A Matzarakis, TP Lin, Outdoor thermal comfort characteristics in the hot and humid region from a gender perspective, Int J Biometeorol. 58 (2014) 1927-1939. doi: 10.1007/s00484-014-0795-7.

[11]M Rutty, D Scott, Bioclimatic comfort and the thermal perceptions and preferences of beach tourists, Int $\mathrm{J}$ Biometeorol. 59 (2015) 37-45. doi: 10.1007/s00484-014-0820-x.

[12]K Pantavou, G Theoharatos, M Santamouris, D Asimakopoulos, Outdoor thermal sensation of pedestrians in a Mediterranean climate and a comparison with UTCI, Build Environ. 66 (2013) 82-95. doi: 10.1016/j.buildenv.2013.02.014.

[13]H Andrade, MJ Alcoforado, S Oliveira, Perception of temperature and wind by users of public outdoor spaces: relationships with weather parameters and personal characteristics, Int J Biometeorol. 55 (2011) 665-680. doi: 10.1007/s00484-010-0379-0.

[14]National Geomatics Centre of China, Basic geographic framework data. http://map.tianditu.com/map/index.html, 2010 (accessed 25 May 2017).

[15]H Jin, ZM Liu, YM Jin, J Kang, J Liu, The Effects of Residential Area Building Layout on Outdoor Wind Environment at the Pedestrian Level in Severe Cold Regions of China. Sustainability. 9 (2017) 2310. doi: $10.3390 /$ su9122310.

[16]Ministry of Housing and Urban-Rural Development of the People's Republic of China. GB 50352-2005 Code for Design of Civil Buildings. China Architecture \& Building Press. 2005.

[17]ZJ Wang, Y Ji, J Ren, Thermal adaptation in overheated residential buildings in severe cold area in China. Energy Build. 146 (2017) 322-332. doi: 10.1016/j.enbuild.2017.04.053.

[18]YM Jin, H Jin, J Kang, ZY Yu, Effects of openings on the wind-sound environment in the traditional residential streets in a severe cold city of China, Environ. Plan. B Urban Anal. City Sci. (2018). doi: $10.1177 / 2399808318805490$.

[19]ISO, International Standard 7726, Ergonomics of the thermal environment-instruments and method for measuring physical quantities, International Standard Organization, Geneva, 1998.

[20]TP Lin, Thermal perception, adaptation and attendance in a public square in hot and humid regions, Build Environ. 44 (2009) 2017-2026. doi: 10.1016/j.buildenv.2009.02.004.

[21]M Luo, X Zhou, Y Zhu, J Sundell, Revisiting an overlooked parameter in thermal comfort studies, the metabolic rate, Energy Build. 118 (2016)152-159. doi: 10.1016/j.enbuild.2016.02.041.

[22]Y Wang, R De Groot, F Bakker, H Wörtche, R Leemans, Thermal comfort in urban green spaces: a survey on a dutch university campus, Int J Biometeorol. 61 (2017) 87-101. doi: 10.1007/s00484-016-1193-0.

[23]A Pitts, Thermal Comfort in Transition Spaces, buildings. 3 (2013) 122-142. doi: 10.3390/buildings3010122.

[24]P Weihs, H Staiger, B Tinz, E Batchvarova, H Rieder, L Vuilleumier, M Maturilli, G Jendritzky, The uncertainty of UTCI due to uncertainties in the determination of radiation fluxes derived from measured and observed meteorological data, Int J Biometeorol. 56 (2012) 537-555. doi:10.1007/s00484-011-0416-7.

[25]P Bröde, D Fiala, K Błażejczyk, I Holmér, G Jendritzky, B Kampmann, B Tinz, G Havenith, Deriving the operational procedure for the Universal Thermal Climate Index (UTCI), Int J Biometeorol. 56 (2012) 481-494. doi: 10.1007/s00484-011-0454-1. 
[26]P Bröde, EL Krüger, FA Rossi, D Fiala, Predicting urban outdoor thermal comfort by the universal thermal climate index utci-a case study in southern brazil, Int J Biometeorol. 56 (2012) 471-480. doi: 10.1007/s00484-0110452-3.

[27]H Jin, SQ Liu, Kang J, Thermal Comfort Range and Influence Factor of Urban Pedestrian Streets in Severe Cold Regions, Energy Build. 198 (2019) 197-206. doi: 10.1016/j.enbuild.2019.05.054.

[28]S Park, SE Tuller, M Jo, Application of Universal Thermal Climate Index (UTCI) for microclimatic analysis in urban thermal environments, Landsc Urban Plan. 125 (2014) 146-155. doi: 10.1016/j.landurbplan.2014.02.014.

[29]ASHRAE, ASHRAE Standard 55-2004, Thermal environmental conditions for human occupancy, Atlanta: American Society of Heating, Refrigerating and Air-Conditioning Engineers, Inc., 2004.

[30]EL Kruger, FA Rossi, Effect of personal and microclimatic variables on observed thermal sensation from a field study in southern Brazil, Build. Environ. 46 (2011) 690-697. doi: 10.1016/j.buildenv.2010.09.013.

[31]S Amindeldar, S Heidari, M Khalili, The effect of personal and microclimatic variables on outdoor thermal comfort: a field study in Tehran in cold season, Sustain. Cities Soc. 32 (2017) 153-159. doi: 10.1016/j.scs.2017.03.024.

[32]P Cohen, O Potchter, A Matzarakis, Human thermal perception of Coastal Mediterranean outdoor urban environments, Appl. Geogr. 37 (2013) 1-10. doi: 10.1016/j.apgeog.2012.11.001.

[33]V Cheng, EY-K Ng, CM Chan, B Givoni, Outdoor thermal comfort study in a sub-tropical climate: a longitudinal study based in Hong Kong, I Int J Biometeorol. 56 (2012), 43-56. doi: 10.1007/s00484-010-0396-z.

[34]K Pantavou, E Chatzi, G Theoharatos, Case study of skin temperature and thermal perception in a hot outdoor environment, Int J Biometeorol. 58 (2014) 1163-1173. doi: 10.1007/s00484-013-0708-1.

[35]B Givoni, M Noguchi, H Saaroni, O Pochter, Y Yaacov, N Feller, S Becker, Outdoor comfort research issues, Energy Build. 35 (2003), 77-86. doi: 10.1016/S0378-7788(02)00082-8.

[36]F Salata, I Golasi, R Proietti, A de L Vollaro, Implications of climate and outdoor thermal comfort on tourism: the case of Italy, Int J Biometeorol. 61 (2017), 2229-2244. doi: 10.1007/s00484-017-1430-1.

[37]ISO (1999) BS EN ISO 9920:2009, Ergonomics of the thermal environment. Estimation of thermal insulation and water vapour resistance of a clothing ensemble, International Standard Organization, Geneva, 2009.

[38]GC Donaldson, H Rintamäki, S. Näyhä, Outdoor clothing: its relationship to geography, climate, behavior and cold-related mortality in Europe, Int J Biometeorol. 45 (2001) 45-51, doi: 10.1007/s004840000072.

[39]G Havenith, D Fiala, K Błazejczyk, M Richards, P Bröde, I Holmér, H Rintamaki, Y Benshabat, G Jendritzky, The UTCl-clothing model, Int J Biometeorol. 56 (2012) 461-470. doi: 10.1007/s00484-011-0451-4.

[40]M Nikolopoulou, S Lykoudis, Thermal comfort in outdoor urban spaces: Analysis across different European countries. Build. Environ. 41 (2006) 1455-1470. DOI: 10.1016/j.buildenv.2005.05.031.

[41]D Lai, D Guo, Y Hou, C Lin, Q Chen, Studies of outdoor thermal comfort in northern China, Build Environ. 77 (2014) 110-118. doi: 10.1016/j.buildenv.2014.03.026.

[42]J Goodwin, RS Taylor, VR Pearce, KLQ Read. Seasonal cold, excursional behavior, clothing protection and physical activity and old subjects. Intl J Circumpolar Health. 59 (2000)195-203.

[43]General Administration of Quality Supervision, Inspection and Quarantine of the People's Republic of China, Ministry of Health P.R. China, State Environmental Protection Administration of China. GB/T18883-2002 Indoor Air Quality Standard. Standards Press of China. 2002.

[44]TM Mäkinen, VP Raatikka, M Rytkönen, J Jokelainen, H Rintamäki, R Ruuhela, S Näyhä, J Hassi. Factors affecting outdoor exposure in winter: population-based study. Int J Biometeorol. 51 (2006) 27-36. doi: 10.1007/s00484-006-0040-0.

[45]ISO, International Standard 8996, Ergonomics of the thermal environment - Determination of metabolic rate, International Standard Organization, Geneva, 2004.

[46]SE Stahl, HS An, DM Dinkel, JM Noble, J M Lee, How accurate are the wrist-based heart rate monitors during walking and running activities? are they accurate enough? BMJ Open Sport Exerc. Med. 2(2016), e000106. doi: 10.1136/bmjsem-2015-000106.

[47]S Thorsson, M Lindqvist, S Lindqvist, Thermal bioclimatic conditions and patterns of behaviour in an urban park in Göteborg, Sweden, Int J Biometeorol. 48 (2004), 149-156. doi: 10.1007/s00484-003-0189-8.

[48]M Nikolopoulou, K Steemers, Thermal comfort and psychological adaptation as a guide for designing urban spaces, Energy Build. 35 (2003), 95-101. doi: 10.1016/S0378-7788(02)00084-1.

[49] Eliasson, I Knez, U Westerberg, S Thorsson, F Lindberg, Climate and behaviour in a Nordic city, Landsc Urban Plan. 82 (2007) 72-84. doi: 10.1016/j.landurbplan.2007.01.020.

[50]J Zacharias, T Stathopoulos, H Wu, Microclimate and downtown open space activity, Environ. Behav. 33 (2001) 296-315. doi: 10.1177/0013916501332008.

[51]KC Parsons, The effects of gender, acclimation state, the opportunity to adjust clothing and physical disability on requirements for thermal comfort. Energy Buildings 34 (2002) 593-599. doi: 10.1016/S0378-7788(02)000099.

[52]M Nakayoshi, M Kanda, R Shi, R de Dear, Outdoor thermal physiology along human pathways: a study using a wearable measurement system, Int J Biometeorol. 59 (2015) 503-515. doi: 10.1007/s00484-014-0864-y. 
Hong Jin, Siqi Liu \& Jian Kang: Building and Environment doi: 10.1016/j.buildenv.2019.106488

[53]K Lundgren, K Kuklane, C Gao, I Holmér, Effects of Heat Stress on Working Populations when facing Climate Change, Ind. Health. 51 (2013) 3-15. doi: 10.2486/indhealth.2012-0089.

[54]J Kang, Urban Sound Environment, Taylor \& Francis incorporating Spon, London, 2007. doi: 10.4324/9780203004784.

[55]W Yang, J Kang, Acoustic comfort evaluation in urban open public spaces, Appl. Acoust. 66 (2005) 211-229. doi: 10.1016/j.apacoust.2004.07.011.

[56]L Yu, J Kang, Effects of social, demographical and behavioral factors on the sound level evaluation in urban open spaces, J. Acoust. Soc. Am. 123(2008), 772-783. doi: 10.1121/1.2821955. 